\title{
Is a low level of free thyroxine in the maternal circulation associated with altered endothelial function in gestational diabetes?
}

\author{
Enrique Guzmán-Gutiérrez ${ }^{1,2}{ }^{*}$, Carlos Veas $^{2}$, Andrea Leiva ${ }^{3}$, Carlos Escudero $^{1,4}$ and Luis Sobrevia ${ }^{3,5}$ * \\ 'Group of Research and Innovation in Vascular Health, Universidad San Sebastián, Concepción, Chile \\ ${ }^{2}$ Facultad de Ciencias de la Salud, Universidad San Sebastián, Concepción, Chile \\ ${ }^{3}$ Cellular and Molecular Physiology Laboratory, Division of Obstetrics and Gynaecology, School of Medicine, Faculty of Medicine, Pontificia Universidad Católica \\ de Chile, Santiago, Chile \\ ${ }^{4}$ Vascular Physiology Laboratory, Group of Investigation in Tumor Angiogenesis, Department of Basic Sciences, University of Bío-Bío, Chillán, Chile \\ ${ }^{5}$ University of Queensland Centre for Clinical Research, Faculty of Medicine and Biomedical Sciences, University of Queensland, Herston, QL, Australia
}

\section{Edited by:}

Bimal Malhotra, Pfizer, USA

\section{Reviewed by:}

Martin C. Michel, Boehringer

Ingelheim Pharma GmbH \& Co KG, Germany

Carlos F. Sánchez-Ferrer, Universidad Autonoma de Madrid, Spain

\section{${ }^{*}$ Correspondence:}

Enrique Guzmán-Gutiérrez, Facultad de Ciencias de la Salud, Universidad San Sebastián, General Cruz 1577, Concepción 4081322, Chile e-mail:enrique.guzman@uss.cl; Luis Sobrevia, Cellular and Molecular Physiology Laboratory, Division of Obstetrics and Gynaecology, School of Medicine, Faculty of Medicine, Pontificia Universidad Católica de Chile, P.O. Box 114-D, Santiago, Chile e-mail:sobrevia@med.puc.cl

Synthesis of thyroid hormones, thyroxine $\left(T_{4}\right)$ and tri-iodothyronine $\left(T_{3}\right)$, in the human fetus starts from 17 to 19th weeks of gestation. Despite the majority of normal pregnant women reaching adequate levels of circulating thyroid hormones, in some cases, women with normal pregnancies have low level of free $T_{4}$ during first trimester of pregnancy, suggesting that $\mathrm{T}_{4}$ action may be compromised in those women and their fetuses. In addition, pathological low levels of thyroid hormones are detected in isolated maternal hypothyroxemia (IMH) and clinical hypothyroidism. Nevertheless, human placenta regulates $T_{3} / T_{4}$ concentration in the fetal circulation by modulating the expression and activity of both thyroid hormone transporters (THT) and deiodinases. Then, placenta can control the availability of $T_{3} / T_{4}$ in the feto-placental circulation, and therefore may generate an adaptive response in cases where the mother courses with low levels of $T_{4}$. In addition, $T_{3} / T_{4}$ might control vascular response in the placenta, in particularly endothelial cells may induce the synthesis and release of vasodilators such as nitric oxide (NO) or vasoconstrictors such as endothelin-1 mediated by these hormones. On the other hand, low levels of $\mathrm{T}_{4}$ have been associated with increase in gestational diabetes (GD) markers. Since GD is associated with impaired placental vascular function characterized by increased NO synthesis in placental arteries and veins, as well as elevated placental angiogenesis, it is unknown whether reduced $T_{4}$ level at the maternal circulation could result in an altered placental endothelial function during GD. In this review, we analyze available information regarding thyroid hormones and endothelial dysfunction in GD; and propose that low maternal levels of $T_{4}$ observed in GD may be compensated by increased placental availability of $T_{3} / T_{4}$ via elevation in the activity of THT and/or reduction in deiodinases in the feto-placental circulation.

\section{Keywords: thyroxine, gestational diabetes, endothelial dysfunction, pregnancy}

\section{INTRODUCTION}

Thyroid gland produces tetra-iodothyronine ( $\mathrm{T}_{4}$ or thyroxine) and tri-iodothyronine $\left(\mathrm{T}_{3}\right)$. In the human fetus, the synthesis of these hormones starts from 17 to 19th weeks of gestation $(\mathrm{wg})$, therefore it is well accepted that before this period, the circulating $\mathrm{T}_{3} / \mathrm{T}_{4}$ in the fetus depends on the maternal levels of these hormones (Pérez-López, 2007). Thus, an altered function of the thyroid gland at the maternal side could prejudice physiological levels of $\mathrm{T}_{3} / \mathrm{T}_{4}$ at the fetal circulation, and impair fetal growth and development. Worldwide studies indicate that $\sim 10 \%$ of women may have hypothyroidism in their childbearing age (Mosso et al., 2012; Khalid et al., 2013; Ohashi etal., 2013). It has been also described that $\sim 35$ or $\sim 3 \%$ of women with an apparent normal pregnancy have clinical hypothyroidism or exhibit maternal hypothyroxemia (low level of free $\mathrm{T}_{4}$ ), respectively (Mosso et al., 2012), both maternal conditions associated with several alterations in the fetus development (Parkes et al., 2012). Nevertheless, isolated maternal hypothyroxemia (IMH), a pathological condition manifested during pregnancy (Sahay and Nagesh, 2012), have been associated with occurrence of gestational diabetes (GD; Olivieri et al., 2000), pre-eclampsia (Sardana et al., 2009), or intrauterine growth restriction, IUGR; Chan et al., 2006). Moreover, pregnant women with IMH have higher risk (fourfold) to develop insulin resistance and GD (Karakosta et al., 2012; Tudela et al., 2012). In fact, reduced $\mathrm{T}_{4}$ level in the maternal circulation is associated with an increase in the incidence of GD pregnancies (Olivieri et al., 2000; Tudela et al., 2012) and with altered development of the central nervous system in children from pregnancies affected by these diseases (Smallridge and Ladenson, 2001; Casey et al., 2005). In addition, an incidence as high as $\sim 70 \%$ of women coursing with pregnancies affected with GD exhibit IMH (Olivieri et al., 2000). 
Gestational diabetes (GD) is associated with higher synthesis and release of vasodilators such as nitric oxide (NO) in the human fetal endothelium from GD (described as altered endothelial function) (De Vriese etal., 2000; Guzmán-Gutiérrez et al., 2011; Westermeier et al., 2011; Salomón et al., 2012). In addition, thyroid hormones are also involved in NO synthesis and release (Napoli et al., 2001; Fazio et al., 2004), but the potential contribution of reduced circulating $\mathrm{T}_{4}$ on deregulation of fetal endothelial function seen in GD pregnancies is unclear. We here analyze the available information regarding the potential relationship between maternal and fetal thyroid hormones with the occurrence of endothelial dysfunction in GD. We propose that the low maternal levels of $\mathrm{T}_{4}$ seen in GD may be compensated by higher placental availability of thyroid hormones via elevation in the activity of placental thyroid hormone transport and metabolism.

\section{OVERVIEW OF SYNTHESIS AND RELEASE OF THYROID HORMONES}

The thyroid hormones $3,5,3^{\prime}, 5^{\prime}$-tetraiodothyronine $\left(\mathrm{T}_{4}\right.$ or thyroxine) and 3,5,3'-triiodothyronine $\left(\mathrm{T}_{3}\right)$ are synthesized in the thyroid gland and is regulated by hypothalamus/pituitary/thyroid axis by a negative feedback. In this regulatory axis, hypothalamus releases thyrotropin releasing hormone (TRH), which interacts with TRH receptors in thyrotropin cells in the pituitary gland to release thyroid stimulating hormone (TSH). In turn, TSH is the main regulator of the release of thyroid hormones leading to $\mathrm{TSH}$ receptor (TSHr) activation and increased iodo (iodide) uptake in the thyroid gland (Szkudlinski etal., 2002).

Iodide intracellular uptake is mediated by cotransport with sodium $\left(\mathrm{Na}^{+} / \mathrm{I}^{-}\right)$in the basal membrane of follicular cells in the thyroid gland. In these cells, iodides are oxidized by thyroid peroxidase (TPO) in the presence of hydrogen peroxide. Iodine (oxidized iodine) binds to thyroxine residues belong to the tiroglobulins ( $\mathrm{Tg}$ ), then tyroxine residues can be mono (MIT), di (DIT), tri $\left(\mathrm{T}_{3}\right)$, or tetra-iodinated $\left(\mathrm{T}_{4}\right)$ (Sugenoya et al., 1984; Rousset, 1991). The release of thyroid hormones through the basolateral membrane in thyroid gland follicular cells requires endocytosis of iodinated $\mathrm{Tg}$ at the apical side of these cells. The $\mathrm{Tg}$ is then incorporated into phagolysosomes and digested by proteolytic proteins, with MIT and DIT being re-uptaked into Tg; however, T3 and T4 are released toward circulation (Rousset, 1991). $\mathrm{T}_{4}$ is the main thyroid hormone released by thyroid gland follicular cells ( $\sim 40$-fold compared with $\left.\mathrm{T}_{3}\right)$ and is almost all (99.97\%) bound to thyroxine binding globulin (TBG), albumin and pre-albumin in the circulation. In addition, free $\mathrm{T}_{3}$ accounts for $\sim 0.3 \%$ and the rest is bound to $\mathrm{TBG}$ and albumin.

Free $\mathrm{T}_{3}$ is the hormone with biological activity and is the active form of thyroid hormones. It is derived from $5^{\prime}$-deiodination of free $\mathrm{T}_{4}$ via iodothyronine deiodinases located in the target tissues (Sugenoya et al., 1984; Rousset, 1991; Schussler, 2000; Bianco and Kim, 2006). Deiodinases are grouped in three subtypes: I, II, and III (or D1, D2, and D3, respectively), all of which are involved in the regulation of $\mathrm{T}_{3}$ activity (Bianco and Kim, 2006; Darras and Van Herck, 2012). For instance, D2 is specific to generate $\mathrm{T}_{3}$ from $\mathrm{T}_{4}$; however, D3 generates DIT from $T_{3}$, and reverse $T_{3}\left(r T_{3}\right.$, inactive form of $\left.T_{3}\right)$ from $T_{4}$ (Kilby et al., 2005). D1 has been reported as an enzyme that is much less active compared with the other forms (Bianco and Kim, 2006; Dentice and Salvatore, 2011; Darras and Van Herck, 2012).

\section{VASCULAR EFFECTS OF THYROID HORMONES}

Thyroid hormones reduce peripheral vascular resistance by promoting relaxation in human and murine vascular smooth-muscle cells (Klemperer et al., 1995; Ojamaa et al., 1996; Park et al., 1997), and improve vascular reactivity by endothelium-dependent and -independent mechanisms (Napoli et al., 2001; Fazio et al., 2004). In rat, $\mathrm{T}_{4}$ released from the mesenteric arteries increases vasorelaxation when administrated at supraphysiological concentrations (Zwaveling et al., 1997). Moreover, $\mathrm{T}_{3}$ and $\mathrm{T}_{4}$ improve fibroblast growth factor-2 (FGF-2) expression, a recognized proangiogenic factor, in cultures of ECV304 cells (Davis et al., 2004). Interestingly, human umbilical vein endothelial cells (HUVEC) exposed to high $\mathrm{T}_{3}$ levels exhibit high expression of endothelin-1 (vasoconstrictor) and fibronectin (profibrotic molecule), suggesting that pathological conditions such as hyperthyroidism could be associated with vasoconstriction (Baumgartner-Parzer et al., 1997; Diekman et al., 2001).

In addition, there is evidence that vasoconstriction associated with high levels of thyroid hormones may result from a non-genomic action, which seems mediated by $\alpha v \beta 3$ integrin as reported in HUVEC (Luidens et al., 2010). In this regard, $\alpha v \beta 3$ integrin is a membrane protein that should active the phosphatidylinositol 3 kinase and protein kinase B/Akt (PI3K/Akt) pathway in this cell type (Hiroi etal., 2006; Luidens et al., 2010). Nevertheless, in another study HUVEC and bovine aortic endothelial cells (BAEC) seems to respond to $\mathrm{T}_{3}$ by increasing the phosphorylation of serine ${ }^{1177}$ (Ser ${ }^{1177}$; Ser ${ }^{1177}$-eNOS) at the endothelial nitric oxide synthase isotype (eNOS) in a timeand concentration-dependent manner (Hiroi et al., 2006). Similar results were seen in vascular smooth-muscle cells from rat thoracic aortae where $\mathrm{T}_{3}$ increases $\mathrm{Ser}^{1177}$-eNOS via PI3K/Akt pathway inducing eNOS, inducible (iNOS) and neuronal (nNOS) NOS expression. Thus, it is likely that $\mathrm{T}_{3}$ increases NOS expression via a genomic and a non-genomic (i.e., via $\alpha v \beta 3$ integrin) action (Carrillo-Sepúlveda et al., 2010). Therefore, the thyroid hormone concentration is a determinant factor involved in the modulation of vascular function (Figure 1). However, there is not information addressing thyroid hormone effects on the human feto-placental vasculature.

\section{HUMAN THYROID HORMONES IN PREGNANCY}

Human fetal thyroid hormones are secreted from the 17 to $19 \mathrm{wg}$, indicating that the fetus requires thyroid hormones delivery from the mother during the first and beginning of the second trimester of pregnancy (Pérez-López, 2007). Pregnant women have TSH and free $\mathrm{T}_{4}$ levels that are normal and comparable to those in non-pregnant women; however, in the first trimester of pregnancy, there is an increase in the maternal free $\mathrm{T}_{4}$ level most likely in response to chorionic gonadotropin hormone (hCG; Fantz et al., 1999; Pérez-López, 


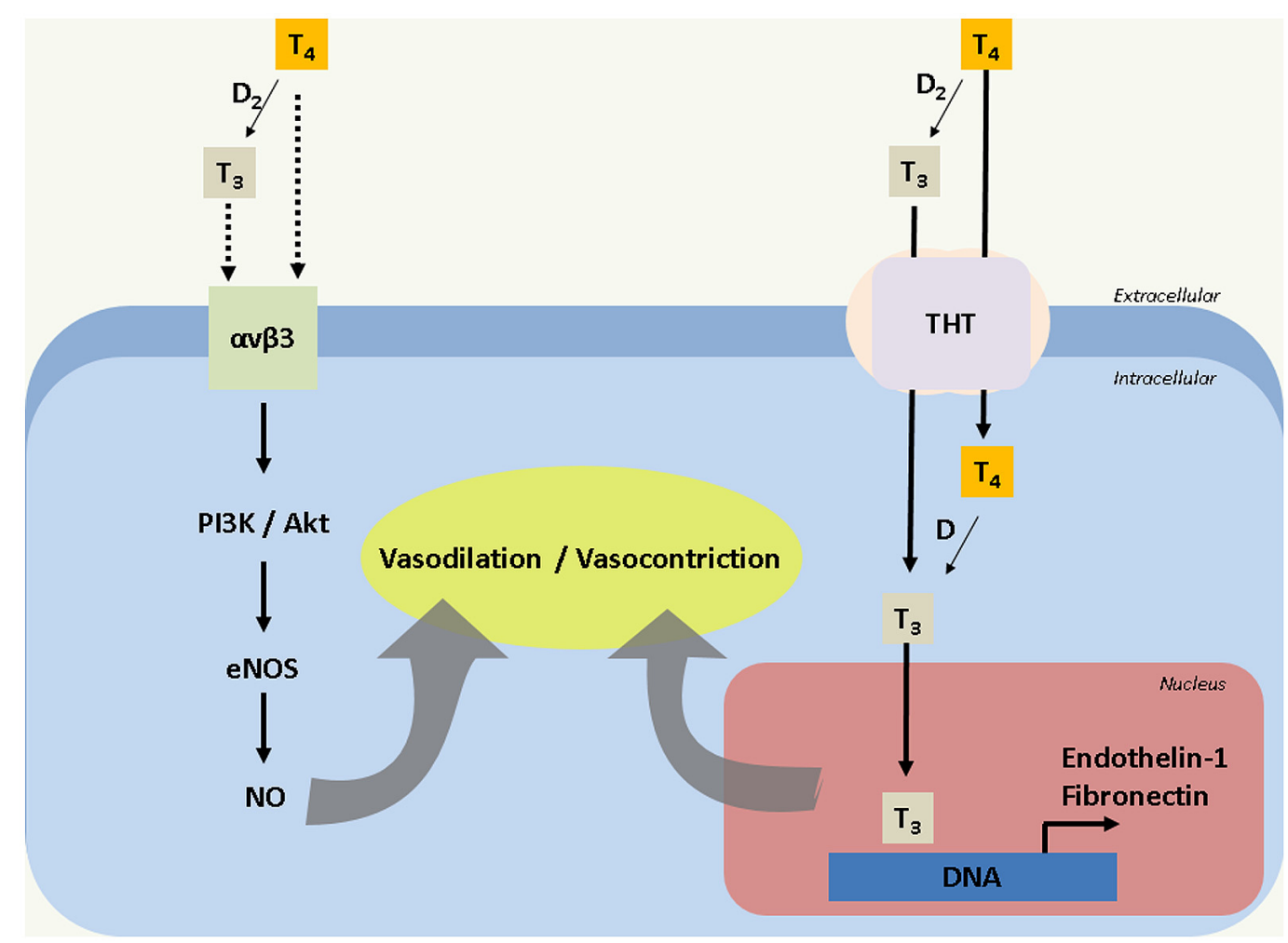

FIGURE 1 |Thyroids hormones effects on endothelial cells. $T_{4}$ (Tyrosine) is metabolized by deiodinase $2\left(D_{2}\right)$ to $T_{3}$ (triiodothyronine) of manner extra and intracellular. $T_{3}$ and $T_{4}$ (Tyrosine) could activates $\alpha v \beta 3$ integrin receptor which initiate a signaling that involve PI3K, Akt and eNOS, generating nitric oxide (NO) as vasodilator. But, also T3 and T4 are uptake by thyroid hormones transporters (THT). T3 bind to DNA and activate transcriptional activity for endothelin-1 and fibronectin which are associated with vasoconstriction.
2007). It has been shown that increased hCG level leads to reduced hypothalamus/pituitary/thyroid axis activity, but improved thyroid hormones delivery to the fetus in the first trimester of pregnancy (Fantz etal., 1999; Pérez-López, 2007; Chan etal., 2009). In this period, the concentration of free $T_{4}$ in the fetal circulation corresponds to a third of the level found in the maternal circulation (Chan et al., 2009). This phenomenon results from a reduced concentration of the TBG binding protein in the fetal circulation, which leads to a free $\mathrm{T}_{4}$ concentration enough to exert its biological effects in embryonic tissues (Kilby et al., 2005; Chan et al., 2009). In the second trimester of pregnancy, free $\mathrm{T}_{4}$ levels in the fetal circulation corresponds to about half of the concentration detected in the maternal circulation (Kilby et al., 2005; Chan et al., 2009). Therefore, it seems clear that thyroid hormone levels are regulated by the placenta tissue (Burrow et al., 1994). Thus, a role of this organ is crucial in the delivery of $\mathrm{T}_{4}$ to the fetus.

\section{THYROID HORMONES METABOLISM IN THE HUMAN PLACENTA}

In addition to the paracrine effect of hCG on the hypothalamus/pituitary/thyroid axis, the human placenta regulates directly the thyroid hormone concentration in the fetal circulation by modulation of thyroid hormone transporters (THT), and by thyroid hormones metabolism mediated by deiodinases
(Burrow et al., 1994). THT are located at the apical and basolateral membranes of the cytotrophoblasts, syncytiotrophoblast and microvascular endothelial cells (James et al., 2007). There are several THT, including monocarboxylate transporters (MCT), where MCT8 and MCT10 are the main forms. Moreover, a role has been reported for L-amino acid transporters (LAT) and organic anion transporter polypeptides system (OATPs), which operates with less selectivity for $\mathrm{T}_{4}$ (James et al., 2007). Also in the human placenta MCT8 (Park and Chatterjee, 2005), MCT10, LAT1, LAT2 (Friesema et al., 2003), OATP1A2 and OATP4A1 (Hagenbuch and Meier, 2003; Hagenbuch, 2007) have been identified, but no studies addressing the role of these membrane transporters in any pathology of pregnancy have been documented. Moreover, D2 (located at the endoplasmatic reticulum) and D3 (located at the plasma membrane with a cytoplasmic active site; Koopdonk-Kool et al., 1996; Stulp et al., 1998; Chan et al., 2003) have been identified. D2 and D3 are referred as major factors controlling transplacental transport of $\mathrm{T}_{4}$ to the fetus (Mortimer et al., 1996). Interestingly, D2 and D3 expression is up regulated by $\mathrm{T}_{3}$ (Chan etal., 2003). In addition, since changes in the level of $\mathrm{T}_{3} / \mathrm{T}_{4}$ cause altered THT expression (Mortimer et al., 1996), modulation of D2/D3 and THT expression by $\mathrm{T}_{3} / \mathrm{T}_{4}$ could be a phenomenon serving as a defense mechanism for the fetus in pregnancies where the mother courses with hypothyroxemia. 


\section{ISOLATED MATERNAL HYPOTHYROXEMIA AND CLINICAL HYPOTHYROIDISM}

The pathologies associated with low levels of free $\mathrm{T}_{4}$ correspond to IMH and clinical hypothyroidism. IMH (1-2\% of normal pregnancies) is characterized by low free $\mathrm{T}_{4}(<10$ th percentile in normal range), but normal TSH level. Instead, clinical hypothyroidism characterizes by high levels of TSH, but low levels of free $\mathrm{T}_{4}$ (Casey et al., 2005). In another pathological condition referred as "low $\mathrm{T}_{3}$ syndrome," an increase in the expression of the membrane transporters MCT8 is reported, which could be a compensatory response to low levels of thyroid hormones (Mebis etal., 2009). The latter seems paralleled by an increase in the D1 and D2 levels as reported in human skeletal muscle and liver (Peeters et al., 2003; Weetman et al., 2003). While, using a knockout mice model for MCT8 $\left(\mathrm{Mct}^{-/-}\right)$an increase in the plasma free $\mathrm{T}_{4}$ and $\mathrm{T}_{3}$ levels, and D1 and D2 expression and activity in the liver was shown (Dumitrescu et al., 2006). Therefore, these results support the fact that low levels of $\mathrm{T}_{4}$ lead to changes in the THT and deiodinase expression and activity in target organs. However, there is no information addressing this possibility in the human placenta from pregnancies coursing with maternal hypothyroxemia.

On the other hand, minor changes such as D2 gene polymorphism (Thr92Ala) are associated with human type 2 diabetes mellitus and insulin resistance (Mentuccia etal., 2002). In this regard, despite there is not information regarding D2 gene polymorphism in women coursing with pregnancies without a diagnosis of thyroid gland pathology, a negative correlation between free $\mathrm{T}_{4}$ level and metabolic markers of GD and insulin resistance (i.e., degree of glycosylated $\mathrm{HbA}_{1 \mathrm{c}}$, fasting insulin, and HOMA-IR) has been shown (Bassols et al., 2011). Then, it is proposed that a potential relationship between low maternal free $\mathrm{T}_{4}$ levels and occurrence of GD and perhaps its complications including endothelial dysfunction exists.

\section{MATERNAL T ${ }_{4}$ LEVEL AND GD}

GD is a disease coursing with glucose intolerance first recognized or manifested during pregnancy [Metzger et al., 2007; Reece et al., 2009; American Diabetes Association [ADA], 2012]. This pathology accounts for $\sim 5 \%$ of pregnant women worldwide and it is associated with high risk of fetal perinatal alterations (e.g., macrosomia, insulin resistance) and higher incidence of diseases in the adulthood (e.g., GD, obesity, dyslipidemia, hypertension, metabolic syndrome) (Poston, 2010; Negrato et al., 2012). GD is associated with reduced maternal circulating $\mathrm{T}_{4}$ levels in the first trimester of pregnancy. To date, $5 \%$ of women coursing with GD pregnancies have been shown to correlate with IMH (Krcma et al., 2010). In addition, free $\mathrm{T}_{4}$ levels are lower in women with GD pregnancy compared with women with normal pregnancies (Velkoska-Nakova et al., 2010) and a reduced free $\mathrm{T}_{4}$ level is shown in $70 \%$ of patients with GD pregnancies (Olivieri et al., 2000). Therefore, maternal hypothyroxemia could be associated with GD.

Other pathologies associated with low levels of free $\mathrm{T}_{4}$, such as clinical hypothyroidism (i.e., low free $\mathrm{T}_{4}$ and high $\mathrm{TSH}$ levels), also have been associated with GD. Indeed, $6-15 \%$ of
GD pregnancies are associated with hypothyroidism (VelkoskaNakova etal., 2010; Tudela etal., 2012; Stohl etal., 2013). Moreover, if pregnant women have hypothyroidism, they have 4.3-fold higher risk for developing GD (Karakosta et al., 2012). There are no publications addressing the $\mathrm{T}_{4}$ plasma levels at the fetal circulation in a pregnancy coursing with GD. However, since GD courses with endothelial dysfunction (De Vriese et al., 2000; Westermeier et al., 2011; Guzmán-Gutiérrez et al., 2011, 2014; Salomón et al., 2012) and thyroid hormones modulate endothelial function (Napoli et al., 2001; Fazio et al., 2004), it is likely that a low free $\mathrm{T}_{4}$ level at the maternal circulation eventually could result in altered endothelial function in GD pregnancies.

\section{GD AND ENDOTHELIAL DYSFUNCTION}

One of the main alterations detected in GD pregnancies is the associated endothelial dysfunction of the fetoplacental circulation (De Vriese et al., 2000; Guzmán-Gutiérrez et al., 2011, 2014; Westermeier etal., 2011; Salomón etal., 2012). Since the vasculature in the human placenta lacks innervation (Marzioni et al., 2004), several local metabolic mechanisms, such as synthesis and release of vasoactive molecules (e.g., NO, adenosine) (Vásquez et al., 2004; Guzmán-Gutiérrez et al., 2011, 2014; Sobrevia etal., 2011) or release of nanovesicles (e.g., exosomes), most likely mediating autocrine and/or paracrine modulation of vasculature (Salomon et al., 2013), could lead to acute and rapid modulation of vascular tone in this vascular bed (Guzmán-Gutiérrez etal., 2011, 2014; Burnstock and Novak, 2013).

Arteries and veins in the human placenta from pregnancies with GD exhibit increased NO synthesis (Figueroa et al., 2000). Furthermore, similar results were early reported in primary cultures of HUVEC from pregnant women diagnosed with GD (Sobrevia et al., 1995). Therefore, it has been proposed that vascular dysfunction in GD could result from a functional dissociation between NO synthesis and its bioavailability in the human placental circulation (Guzmán-Gutiérrez et al., 2011, 2014; Sobrevia et al., 2011). Even when endothelial dysfunction, referred to as an alteration of NO synthesis and the uptake of cationic amino acid L-arginine (i.e., Larginine/NO pathway), is associated with GD, a clear mechanism behind these effects of GD is still unavailable (Guzmán-Gutiérrez et al., 2014).

\section{HUMAN PLACENTA ENDOTHELIAL FUNCTION AND T4 IN GD: A HYPOTHESIS TO BE TESTED}

In normal pregnancies maternal free $\mathrm{T}_{4}$ is taken up by THT by the syncytiotrophoblast, where it is metabolized by D2 and D3 to be converted into $T_{3}$ or $r T_{3}$, respectively. $T_{4}$ is then released via THT at the basolateral membrane of the syncytiotrophoblast into the intervillous space from where it is taken up by the microvascular endothelial cells via THT. In these cells a fraction of $\mathrm{T}_{4}$ is metabolized again to produce $\mathrm{T}_{3}$ and $\mathrm{rT}_{3}$ via $\mathrm{D} 2$ and $\mathrm{D} 3$, respectively (Figure 2). As a result of this process, $\mathrm{T}_{4}$ and $\mathrm{T}_{3}$ are released into the fetal blood. However, currently there is no information regarding transport of thyroid hormones across the human placenta in GD pregnancies. We propose that low levels of $\mathrm{T}_{4}$, lead to an increase in the number and activity of 


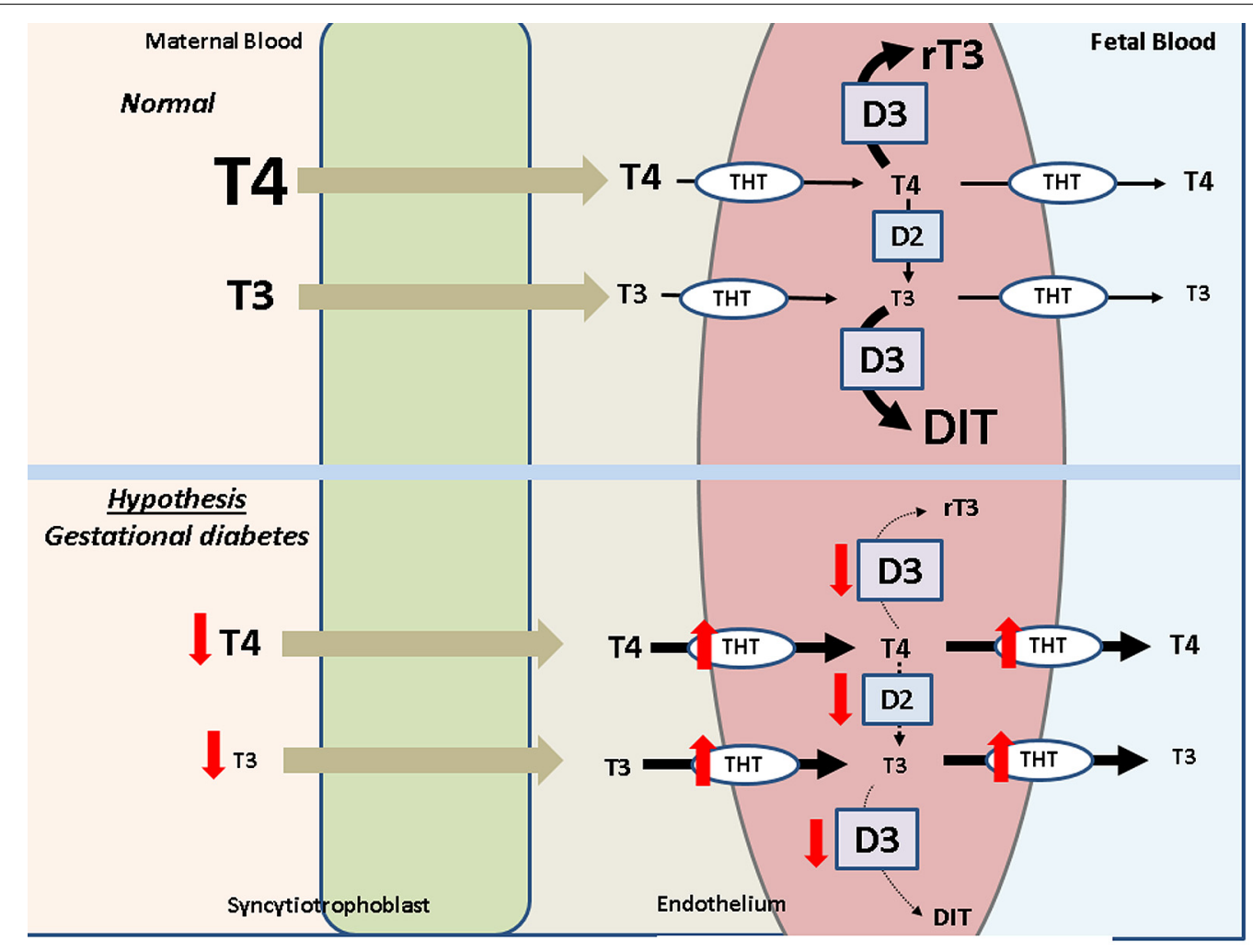

FIGURE 2 | Potential thyroid hormones transplacental transport in gestational diabetes. In cells from normal pregnancies (Normal) T3 and T4 in the maternal blood are transported to the fetal blood by thyroid hormone transporters (THT) through the microvascular endothelium (Endothelium). T3 and T4 are metabolized by deiodinases 2 (D2, forming T3) and 3 (D3, forming reverse T3 9 [T3 from T4 and diiodothyronine (DIT) from T3)], thus leading to modulation of these hormones delivery to the fetal blood. As hypothesis, in Gestational diabetes the mother courses with reduced T3 and T4 levels (red arrows). There is an increase THT and reduced D2/D3 activity, thus compensating T4 level in the fetal blood.
THT membrane transporters available at the plasma membrane of the human placental endothelial cells, and reduced deiodinase expression and activity, in order to supply $\mathrm{T}_{4}$ necessities associated with fetal development in GD. These changes could constitute a mechanism by which the endothelium from the human placenta intends to maintain normal intracellular and circulating levels of $\mathrm{T}_{4}$ in the fetus. The latter would be potentially reached by a greater delivery of maternal $T_{4}$ to the fetal blood.

\section{FINAL COMMENTS AND CONCLUSION}

Based on what was described in this review, our central research questions are: (1) is a low level of free $\mathrm{T}_{4}$ in the maternal circulation associated with GD? (2) is GD a disease associated with increased placental THT, but reduced deiodinase expression and activity? and (3) would the potential changes caused by reduced free $\mathrm{T}_{4}$ level in the maternal circulation and altered THT and deiodinases in the placenta in GD lead to placental endothelial dysfunction? Furthermore, nothing is known regarding the feto-placental vascular function/dysfunction in pregnancies where the mother courses with hypothyroxemia. Despite many benefits for using human placental tissue after birth, we acknowledge that information behind cellular mechanisms and adaptative response occurred at the beginning of pregnancy is difficult to extrapolate; however, it offers a good approximation for studying consequences of human pathologies. Potential more complex models, might include analysis of placentas collected from animal deficient in leptin receptor $(d b /+)$, since they develop GD during pregnancy (Bobadilla et al., 2010), offering a model that may to understand molecular mechanisms of THT and deiodinases in first trimester of pregnancy. Moreover, a therapeutical approach of pregnant women coursing with hypothyroxemia targeted to improve free $\mathrm{T}_{4}$ circulating levels will likely reduce the risk of developing GD and the deleterious consequences of this disease in the feto-placental endothelial function. We also speculate that a normalization of free $\mathrm{T}_{4}$ levels in the first trimester of pregnancy could reduce the risk to face GD-associated complication.

\section{AUTHOR CONTRIBUTIONS}

Enrique Guzmán-Gutiérrez and Luis Sobrevia generated the text and figures, Carlos Veas, Andrea Leiva, and Carlos Escudero contributed for design of text.

\section{ACKNOWLEDGMENTS}

This work was supported by Fondo Nacional de Desarrollo Científico y Tecnológico (FONDECYT; grant numbers 1140586, 11110059, 1110977, 1100684, 3130583), Chile; Programa de 
Investigación Interdisciplinario (PIA) from Comisión Nacional de Investigación en Ciencia y Tecnología (CONICYT; grant number Anillos ACT-73); International NETWORK program from CONICYT (grant number 130102), and Dirección General de Investigación Universidad San Sebastián, Chile.

\section{REFERENCES}

American Diabetes Association [ADA]. (2012). Diagnosis and classification of diabetes mellitus. Diabetes Care 35, S64-S71.

Bassols, J., Prats-Puig, A., Soriano-Rodríguez, P., García-González, M. M., Reid, J., Martínez-Pascual, M., et al. (2011). Lower free thyroxin associates with a less favorable metabolic phenotype in healthy pregnant women. J. Clin. Endocrinol. Metab. 96, 3717-3723. doi: 10.1210/jc.2011-1784

Baumgartner-Parzer, S. M., Wagner, L., Reining, G., Sexl, V., Nowotny, P., Müller, M., et al. (1997). Increase by tri-iodothyronine of endothelin-1, fibronectin and von Willebrand factor in cultured endothelial cells. J. Endocrinol. 154, 231-239. doi: 10.1677/joe.0.1540231

Bianco, A. C., and Kim, B. W. (2006). Deiodinases: implications of the local control of thyroid hormone action. J. Clin. Invest. 116, 2571-2579. doi: 10.1172/JCI 29812

Bobadilla, R. A., van Bree, R., Vercruysse, L., Pijnenborg, R., and Verhaeghe, J. (2010). Placental effects of systemic tumour necrosis factor- $\alpha$ in an animal model of gestational diabetes mellitus. Placenta 31, 1057-1063. doi: 10.1016/j.placenta.2010.09.017

Burnstock, G., and Novak, I. (2013). Purinergic signalling and diabetes. Purinergic Signal. 9, 307-324. doi: 10.1007/s11302-013-9359-2

Burrow, G. N., Fisher, D. A., and Larsen, P. R. (1994). Maternal and fetal thyroid function. N. Engl. J. Med. 331, 1072-1078. doi: 10.1056/NEJM199410203311608 Carrillo-Sepúlveda, M. A., Ceravolo, G. S., Fortes, Z. B., Carvalho, M. H., Tostes, R. C., Laurindo, F. R., et al. (2010). Thyroid hormone stimulates NO production via activation of the PI3K/Akt pathway in vascular myocytes. Cardiovasc. Res. 85 , 560-570. doi: 10.1093/cvr/cvp304

Casey, B. M., Dashe, J. S., Wells, C. E., McIntire, D. D., Byrd, W., Leveno, K. J., et al. (2005). Subclinical hypothyroidism and pregnancy outcomes. Obstet. Gynecol. 105, 239-245. doi: 10.1097/01.AOG.0000152345.99421.22

Chan, S. Y., Franklyn, J. A., Pemberton, H. N., Bulmer, J. N., Visser, T. J., McCabe, C. J., et al. (2006). Monocarboxylate transporter 8 expression in the human placenta: the effects of severe intrauterine growth restriction. J. Endocrinol. 189, 465-471. doi: 10.1677/joe.1.06582

Chan, S. Y., Vasilopoulou, E., and Kilby, M. D. (2009). The role of the placenta in thyroid hormone delivery to the fetus. Nat. Clin. Pract. Endocrinol. Metab. 5, 45-54. doi: 10.1038/ncpendmet1026

Chan, S., Kachilele, S., Hobbs, E., Bulmer, J. N., Boelaert, K., McCabe, C. J., et al. (2003). Placental iodothyronine deiodinase expression in normal and growthrestricted human pregnancies. J. Clin. Endocrinol. Metab. 88, 4488-4495. doi: 10.1210/jc.2003-030228

Darras, V. M., and Van Herck, S. L. (2012). Iodothyronine deiodinase structure and function: from ascidians to humans. J. Endocrinol. 215, 189-206. doi: 10.1530/JOE-12-0204

Davis, F. B., Mousa, S. A., O’Connor, L., Mohamed, S., Lin, H. Y., Cao, H. J., et al. (2004). Proangiogenic action of thyroid hormone is fibroblast growth factordependent and is initiated at the cell surface. Circ. Res. 94, 1500-1506. doi: 10.1161/01.RES.0000130784.90237.4a

De Vriese, A. S., Verbeuren, T. J., Van de Voorde, J., Lameire, N. H., and Vanhoutte, P. M. (2000). Endothelial dysfunction in diabetes. Br. J. Pharmacol. 130, 963-974. doi: 10.1038/sj.bjp.0703393

Dentice, M., and Salvatore, D. (2011). Deiodinases: the balance of thyroid hormone: local impact of thyroid hormone inactivation. J. Endocrinol. 209, 273-282. doi: 10.1530/JOE-11-0002

Diekman, M. J., Zandieh-Doulabi, B., Platvoet-TerSchiphorst, M., Fliers, E., Bakker, O., and Wiersinga, W. M. (2001). The biological relevance of thyroid hormone receptors in immortalized human umbilical vein endothelial cells. J. Endocrinol. 168, 427-433. doi: 10.1677/joe.0.1680427

Dumitrescu, A. M., Liao, X. H., Weiss, R. E., Millen, K., and Refetoff, S. (2006). Tissue-specific thyroid hormone deprivation and excess in monocarboxylate transporter (mct) 8-deficient mice. Endocrinology 147, 4036-4043. doi: 10.1210/en.2006-0390
Fantz, C. R., Dagogo-Jack, S., Ladenson, J. H., and Gronowski, A. M. (1999). Thyroid function during pregnancy. Clin. Chem. 45, 2250-2258.

Fazio, S., Palmieri, E. A., Lombardi, G., and Biondi, B. (2004). Effects of thyroid hormone on the cardiovascular system. Recent Prog. Horm. Res. 59, 31-50. doi: 10.1210/rp.59.1.31

Figueroa, R., Martinez, E., Fayngersh, R. P., Tejani, N., Mohazzab-H, K. M., and Wolin, M. S. (2000). Alterations in relaxation to lactate and H2O2 in human placental vessels from gestational diabetic pregnancies. Am. J. Physiol. 278, H706H713.

Friesema, E. C., Ganguly, S., Abdalla, A., Manning-Fox, J. E., Halestrap, A. P., and Visser, T. J. (2003). Identification of monocarboxylate transporter 8 as a specific thyroid hormone transporter. J. Biol. Chem. 278, 40128-40135. doi: 10.1074/jbc.M300909200

Guzmán-Gutiérrez, E., Abarzúa, F., Belmar, C., Nien, J. K., Ramírez, M. A., Arroyo, P., etal. (2011). Functional link between adenosine and insulin: a hypothesis for fetoplacental vascular endothelial dysfunction in gestational diabetes. Curr. Vasc. Pharmacol. 9, 750-762. doi: 10.2174/15701611179 7484062

Guzmán-Gutiérrez, E., Arroyo, P., Salsoso, R., Fuenzalida, B., Sáez, T., Leiva, A., et al. (2014). Role of insulin and adenosine in the human placenta microvascular and macrovascular endothelial cell dysfunction in gestational diabetes mellitus. Microcirculation 21, 26-37. doi: 10.1111/micc.12077

Hagenbuch, B. (2007). Cellular entry of thyroid hormones by organic anion transporting polypeptides. Best Pract. Res. Clin. Endocrinol. Metab. 21, 209-221. doi: 10.1016/j.beem.2007.03.004

Hagenbuch, B., and Meier, P. J. (2003). The superfamily of organic anion transporting polypeptides. Biochim. Biophys. Acta 1609, 1-18. doi: 10.1016/S00052736(02)00633-8

Hiroi, Y., Kim, H. H., Ying, H., Furuya, F., Huang, Z., Simoncini, T., et al. (2006). Rapid nongenomic actions of thyroid hormone. Proc. Natl. Acad. Sci. U.S.A. 103, 14104-14109. doi: 10.1073/pnas.0601600103

James, S. R., Franklyn, J. A., and Kilby, M. D. (2007). Placental transport of thyroid hormone. Best Pract. Res. Clin. Endocrinol. Metab. 21, 253-264. doi: 10.1016/j.beem.2007.03.001

Karakosta, P., Alegakis, D., Georgiou, V., Roumeliotaki, T., Fthenou, E., Vassilaki, M., etal. (2012). Thyroid dysfunction and autoantibodies in early pregnancy are associated with increased risk of gestational diabetes and adverse birth outcomes. J. Clin. Endocrinol. Metab. 97, 4464-4472. doi: 10.1210/jc. 2012-2540

Khalid, A. S., Joyce, C., and O'Donoghue, K. (2013). Prevalence of subclinical and undiagnosed overt hypothyroidism in a pregnancy loss clinic. Ir. Med. J. 106, $107-110$.

Kilby, M. D., Barber, K., Hobbs, E., and Franklyn, J. A. (2005). Thyroid hormone action in the placenta. Placenta 26, 105-113. doi: 10.1016/j.placenta.2004. 08.004

Klemperer, J. D., Klein, I., Gomez, M., Helm, R. E., Ojamaa, K., Thomas, S. J., et al. (1995). Thyroid hormone treatment after coronary-artery bypass surgery. N. Engl. J. Med. 333, 1522-1527. doi: 10.1056/NEJM199512073332302

Koopdonk-Kool, J. M., de Vijlder, J. J., Veenboer, G. J., Ris-Stalpers, C., Kok, J. H., Vulsma, T., et al. (1996). Type II and type III deiodinase activity in human placenta as a function of gestational age. J. Clin. Endocrinol. Metab. 81, 2154-2158.

Krcma, M., Dvorakova, E., Cechurova, D., Vokurkova, L., and Rusavy, Z. (2010). Isolated maternal hypothyroxinemia in women with gestational diabetes mellitus and its connection to necessity of insulinotherapy. Endocr. Abs. 22, P840. [Abstract].

Luidens, M. K., Mousa, S. A., Davis, F. B., Lin, H. Y., and Davis, P. J. (2010). Thyroid hormone and angiogenesis. Vasc. Pharmacol. 52, 142-145. doi: 10.1016/j.vph.2009.10.007

Marzioni, D., Tamagnone, L., Capparuccia, L., Marchini, C., Amici, A., Todros, T., et al. (2004). Restricted innervation of uterus and placenta during pregnancy: evidence for a role of the repelling signal Semaphorin 3A. Dev. Dyn. 231, 839-848. doi: $10.1002 /$ dvdy.20178

Mebis, L., Paletta, D., Debaveye, Y., Ellger, B., Langouche, L., D’Hoore, A., et al. (2009). Expression of thyroid hormone transporters during critical illness. Eur. J. Endocrinol. 161, 243-250. doi: 10.1530/EJE-09-0290

Mentuccia, D., Proietti-Pannunzi, L., Tanner, K., Bacci, V., Pollin, T. I., Poehlman, E. T., et al. (2002). Association between a novel variant of the human type 2 deiodinase gene Thr92Ala and insulin resistance: evidence of interaction with the 
Trp64Arg variant of the beta-3-adrenergic receptor. Diabetes Metab. Res. Rev. 51, 880-883. doi: 10.2337/diabetes.51.3.880

Metzger, B. E., Buchanan, T. A., Coustan, D. R., de Leiva, A., Dunger, D. B., Hadden, D. R., et al. (2007). Summary and recommendations of the Fifth International Workshop-Conference on Gestational Diabetes Mellitus. Diabetes Care. 30, S251S260. doi: 10.2337/dc07-s225

Mortimer, R., Galligan, J., Cannell, G., Addison, R., and Roberts, M. (1996). Maternal to fetal thyroxine transmission in the human term placenta is limited by inner ring deiodination. J. Clin. Endocrinol. Metab. 81, 2247-2249. doi: 10.1210/jcem.81.6.8964859

Mosso, M. L., Martínez, G. A., Rojas, M. P., Margozzini, P., Solari, S., Lyng, T., et al. (2012). Frequency of subclinical thyroid problems among women during the firs trimester of pregnancy. Rev. Med. Chil. 140, 1401-1408. doi: 10.4067/S003498872012001100004

Napoli, R., Biondi, B., Guardasole, V., Matarazzo, M., Pardo, F., Angelini, V., et al. (2001). Impact of hyperthyroidism and its correction on vascular reactivity in humans. Circulation 104, 3076-3080. doi: 10.1161/hc5001.100621

Negrato, C. A., Montenegro, R. M. Jr., Von Kostrisch, L. M., Guedes, M. F., Mattar, R., and Gomes, M. B. (2012). Insulin analogues in the treatment of diabetes in pregnancy. Arq. Bras. Endocrinol. Metabol. 56, 405-414. doi: 10.1590/S000427302012000700001

Ohashi, M., Furukawa, S., Michikata, K., Kai, K., Sameshima, H., and Ikenoue, T. (2013). Risk-based screening for thyroid dysfunction during pregnancy. J. Pregnancy 2013, 619718. doi: 10.1155/2013/619718

Ojamaa, K., Klemperer, J. D., and Klein, I. (1996). Acute effects of thyroid hormone on vascular smooth muscle. Thyroid 6, 505-512. doi: 10.1089/thy.1996. 6.505

Olivieri, A., Valensise, H., Magnani, F., Medda, E., De Angelis, S., D’Archivio, M., et al. (2000). High frequency of antithyroid autoantibodies in pregnant women at increased risk of gestational diabetes mellitus. Eur. J. Endocrinol. 143, 741-747. doi: 10.1530/eje.0.1430741

Park, K. W., Dai, H. B., Ojamaa, K., Lowenstein, E., Klein, I., and Sellke, F. W. (1997). The direct vasomotor effect of thyroid hormones on rat skeletal muscle resistance arteries. Anesth. Analg. 85, 734-738.

Park, M., and Chatterjee, K. (2005). Genetics of congenital hypothyroidism. J. Med. Genet. 42, 379-389. doi: 10.1136/jmg.2004.024158

Parkes, I. L., Schenker, J. G., and Shufaro, Y. (2012). Thyroid disorders during pregnancy. Gynecol. Endocrinol. 28, 993-998. doi: 10.3109/09513590.2012. 692001

Peeters, R. P., Wouters, P. J., Kaptein, E., van Toor, H., Visser, T. J., and Van den Berghe, G. (2003). Reduced activation and increased inactivation of thyroid hormone in tissues of critically ill patients. J. Clin. Endocrinol. Metab. 88, 3202-3211. doi: 10.1210/jc.2002-022013

Pérez-López, F. R. (2007). Iodine and thyroid hormones during pregnancy and postpartum. Gynecol. Endocrinol. 23, 414-428. doi: 10.1080/095135907014 64092

Poston, L. (2010). Developmental programming and diabetes - the human experience and insight from animal models. Best Pract. Res. Clin. Endocrinol. Metab. 24 541-552. doi: 10.1016/j.beem.2010.05.007

Reece, E. A., Leguizamón, G., and Wiznitzer, A. (2009). Gestational diabetes: the need for a common ground. Lancet 373, 1789-1797. doi: 10.1016/S01406736(09)60515-8

Rousset, B. A. (1991). Intracellular traffic and proteolytic cleavage of thyroglobulin, the thyroid prohormone. Ann. Endocrinol. 52, 355-360.

Sahay, R. K., and Nagesh, V. S. (2012). Hypothyroidism in pregnancy. Ind. J. Endocrinol. Metab. 16, 364-370. doi: 10.4103/2230-8210.95667

Salomon, C., Kobayashi, M., Ashman, K., Sobrevia, L., Mitchell, M. D., and Rice, G. E. (2013). Hypoxia-induced changes in the bioactivity of cytotrophoblastderived exosomes. PLoS ONE 8:e79636. doi: 10.1371/journal.pone. 0079636

Salomón, C., Westermeier, F., Puebla, C., Arroyo, P., Guzmán-Gutiérrez, E., Pardo, F., et al. (2012). Gestational diabetes reduces adenosine transport in human placental microvascular endothelium, an effect reversed by insulin. PLoS ONE. 7:e40578 doi: 10.1371/journal.pone.0040578

Sardana, D., Nanda, S., and Kharb, S. (2009). Thyroid hormones in pregnancy and preeclampsia. J. Turk. Ger. Gynecol. Assoc. 10, 68-171.

Schussler, G. C. (2000). The thyroxine-binding proteins. Thyroid 10, 141-149. doi: 10.1089/thy.2000.10.141
Smallridge, R. C., and Ladenson, P. W. (2001). Hypothyroidism in pregnancy: consequences to neonatal health. J. Clin. Endocrinol. Metab. 86, 2349-2353. doi: 10.1210/jcem.86.6.7577

Sobrevia, L., Abarzúa, F., Nien, J. K., Salomón, C., Westermeier, F., Puebla, C., et al. (2011). Review: differential placental macrovascular and microvascular endothelial dysfunction in gestational diabetes. Placenta 32, S159-S164. doi: 10.1016/j.placenta.2010.12.011

Sobrevia, L., Cesare, P., Yudilevich, D. L., and Mann, G. E. (1995). Diabetes-induced activation of system $\mathrm{y}+$ and nitric oxide synthase in human endothelial cells: association with membrane hyperpolarization. J. Physiol. 489, 183-192.

Stohl, H. E., Ouzounian, J., Rick, A. M., Hueppchen, N. A., and Bienstock, J. L. (2013). Thyroid disease and gestational diabetes mellitus (GDM): is there a connection? J. Matern. Fetal. Neonat. Med. 26, 1139-1142. doi: 10.3109/14767058.2013.773309

Stulp, M. R., de Vijlder, J. J., and Ris-Stalpers, C. (1998). Placental iodothyronine deiodinase III and II ratios, mRNA expression compared to enzyme activity. Mol. Cell. Endocrinol. 142, 67-73. doi: 10.1016/S0303-7207(98)00118-X

Sugenoya, A., Yamada, Y., Kaneko, G., Kobayashi, M., Miyakawa, M., and Iida, F. (1984). In vitro study on release of thyroid hormone in solitary autonomously functioning thyroid nodules using cell culture method. Endocrinol. Jpn. 31, 749753. doi: 10.1507/endocrj1954.31.749

Szkudlinski, M. W., Fremont, V., Ronin, C., and Weintraub, B. D. (2002). Thyroid-stimulating hormone and thyroid-stimulating hormone receptor structure-function relationships. Physiol. Rev. 82, 473-502. doi: 10.1152/physrev.00031.2001

Tudela, C. M., Casey, B. M., McIntire, D. D., and Cunningham, F. G. (2012). Relationship of subclinical thyroid disease to the incidence of gestational diabetes. Obstet. Gynecol. 119, 983-988. doi: 10.1097/AOG.0b013e318250aeeb

Vásquez, G., Sanhueza, F., Vásquez, R., González, M., San Martín, R., Casanello, P., et al. (2004). Role of adenosine transport in gestational diabetesinduced L-arginine transport and nitric oxide synthesis in human umbilical vein endothelium. J. Physiol. 560, 111-122 doi: 10.1113/jphysiol.2004. 068288

Velkoska-Nakova, V., Krstevska, B., Dimitrovski, Ch., Simeonova, S., Hadzi-Lega, M., and Serafimoski, V. (2010). Prevalence of thyroid dysfunction and autoimmunity in pregnant women with gestational diabetes and diabetes type 1. Prilozi 31, 51-59.

Weetman, A. P., Shepherdley, C. A., Mansell, P., Ubhi, C. S., and Visser, T. J. (2003). Thyroid over-expression of type 1 and type 2 deiodinase may account for the syndrome of low thyroxine and increasing triiodothyronine during propylthiouracil treatment. Eur. J. Endocrinol. 149, 443-447. doi: 10.1530/eje.0.14 90443

Westermeier, F., Salomón, C., González, M., Puebla, C., Guzmán-Gutiérrez, E., Cifuentes, F., et al. (2011). Insulin restores gestational diabetes mellitus-reduced adenosine transport involving differential expression of insulin receptor isoforms in human umbilical vein endothelium. Diabetes Metab. Res. Rev. 60, 1677-1687. doi: $10.2337 / \mathrm{db} 11-0155$

Zwaveling, J., Pfaffendorf, M., and van Zwieten, P. A. (1997). The direct effects of thyroid hormones on rat mesenteric resistance arteries. Fundam. Clin. Pharmacol. 11, 41-46. doi: 10.1111/j.1472-8206.1997.tb00167.x

Conflict of Interest Statement: The authors declare that the research was conducted in the absence of any commercial or financial relationships that could be construed as a potential conflict of interest.

Received: 31 March 2014; accepted: 21 May 2014; published online: 06 June 2014. Citation: Guzmán-Gutiérrez E, Veas C, Leiva A, Escudero C and Sobrevia L (2014) Is a low level of free thyroxine in the maternal circulation associated with altered endothelial function in gestational diabetes? Front. Pharmacol. 5:136. doi: 10.3389/fphar.2014.00136

This article was submitted to Cardiovascular and Smooth Muscle Pharmacology, a section of the journal Frontiers in Pharmacology.

Copyright (C) 2014 Guzmán-Gutiérrez, Veas, Leiva, Escudero and Sobrevia. This is an open-access article distributed under the terms of the Creative Commons Attribution License (CC BY). The use, distribution or reproduction in other forums is permitted, provided the original author(s) or licensor are credited and that the original publication in this journal is cited, in accordance with accepted academic practice. No use, distribution or reproduction is permitted which does not comply with these terms. 